\title{
Review
}

\section{Progress in understanding melanoma propagation}

\author{
Mark Shackleton ${ }^{a, b, c, *}$, Elsa Quintana ${ }^{c, 1}$ \\ ${ }^{a}$ Melanoma Research Laboratory and Department of Hematology and Medical Oncology, Peter MacCallum Cancer Centre, \\ East Melbourne 3002, Australia \\ ${ }^{\mathrm{b}}$ Department of Pathology, Faculty of Medicine, Dentistry and Health Sciences, University of Melbourne, Parkville 3010, Australia \\ ${ }^{\mathrm{c}}$ Howard Hughes Medical Institute, Life Sciences Institute, Department of Internal Medicine and Center for Stem Cell Biology, \\ University of Michigan, Ann Arbor, MI 48109-2216, USA
}

\section{A R T I C L E I N F O}

\section{Article history:}

Received 12 May 2010

Received in revised form

15 June 2010

Accepted 16 June 2010

Available online 23 June 2010

\section{Keywords:}

Melanoma

Cancer stem cell

Clonal evolution

Interconversion

Plasticity

CD133

\begin{abstract}
A B S T R A C T
Melanoma, like most cancers, is a disease that wreaks havoc mostly through its propensity to spread and establish secondary tumors at sites that are anatomically distant from the primary tumor. The consideration of models of cancer progression is therefore important to understand the essence of this disease. Previous work has suggested that melanoma may propagate according to a cancer stem cell (CSC) model in which rare tumorigenic and bulk non-tumorigenic cells are organized into stable hierarchies within tumors. However, recent studies using assays that are more permissive for revealing tumorigenic potential indicate that it will not be possible to cure patients by focusing research and therapy on rare populations of cells within melanoma tumors. Studies of the nature of tumorigenic melanoma cells reveal that these cells may gain a growth, metastasis and/or therapy resistance advantage by acquiring new genetic mutations and by reversible epigenetic mechanisms. In this light, efforts to link the phenotypes, genotypes and epigenotypes of melanoma cells with differences in their in vivo malignant potential provide the greatest hope of advancing the exciting progress finally being made against this disease.
\end{abstract}

Crown Copyright $\odot 2010$ Published by Elsevier B.V. on behalf of Federation of European Biochemical Societies. All rights reserved.

\section{Melanoma progression}

Melanoma is eminently curable if primary tumors are detected at an early stage and surgically removed. Because of this, monitoring of high-risk patients and of pre-malignant lesions such as dysplastic nevi is frequently recommended. However, a high proportion of melanomas arise de novo and not in association with previously benign nevi (Weatherhead et al., 2007). Because of this, not all primary melanomas present at a stage that is reliably curable by surgery, and over $10 \%$ of patients present with metastatic disease (Hu et al., 2009). Therefore, despite the importance of understanding melanomagenesis to improve primary prevention, appreciating how melanomas propagate after the establishment of a primary

\footnotetext{
Abbreviations: CSC, Cancer Stem Cell; NSG, NOD/SCID IL2R $\gamma^{-/-}$; NK, Natural Killer.

* Corresponding author. Melanoma Research Laboratory and Department of Hematology and Medical Oncology, Peter MacCallum Cancer Centre, East Melbourne 3002, Australia. Tel.: +61 39656 5235; fax: +61 396561411.

E-mail address: mark.shackleton@petermac.org (M. Shackleton).

${ }^{1}$ Present address: Departamento de Farmacología, Facultad de Medicina, Universidad de Valencia, Avd. Blasco Ibáñez, Valencia, Spain. 1574-7891/\$ - see front matter Crown Copyright $\odot 2010$ Published by Elsevier B.V. on behalf of Federation of European Biochemical Societies. All rights reserved. doi:10.1016/j.molonc.2010.06.006
} 
tumor is critical to reduce the physical and economic burden of this disease.

Conceptually, cancer propagation is proposed to occur according to various models, each of which provides an independent explanation of the phenotypic and functional heterogeneity that is often apparent among cells within a malignant tumor. The first is the cancer stem cell (CSC) model (Dick, 2008; Lobo et al., 2007; Reya et al., 2001), in which tumor growth is primarily driven by rare populations of highly tumorigenic cells that not only renew their own malignant potential, but also give rise to bulk populations of other cells that are irreversibly less- and/or non-tumorigenic. Second is the clonal evolution model (Fearon and Vogelstein, 1990; Foulds, 1958; Lengauer et al., 1998; Nowell, 1976), in which a high proportion of cells in a cancer has the potential to drive disease progression and in which certain cells acquire additional genetic mutations that provide an advantage in growth and/or metastasis capability. More recently, the separate notion of cancer cell plasticity, or interconversion, has been increasingly recognized in the literature as contributing to cancer cell heterogeneity and progression of malignant disease (Gupta et al., 2009; Mani et al., 2008; Marusyk and Polyak, 2010; Pinner et al., 2009; Roesch et al., 2010; Sharma et al., 2010). The interconversion model refers to reversible switching of cancer cells between more and less actively malignant behaviors that may be associated with phenotypic distinctions and differences in therapy responsiveness between cells. In fact, although these models are conceptually quite different, they are not mutually exclusive, and it is likely that at least some cancers use more than one of these models at different stages, or even simultaneously, during their evolution in a patient (Marusyk and Polyak, 2010; Shackleton, 2010).

How does melanoma progress? From a clinical perspective, melanoma is generally considered to be a highly aggressive cancer, although a small subset of patients with metastatic melanoma has a relatively indolent disease course (Tsao et al., 2004). Histologically, mitoses are frequently apparent in sections of melanoma tumors and staining for proliferative markers such as Ki67 is usually positive (Ohsie et al., 2008). In this light, it would be surprising if melanoma progressed according to a model in which tumorigenic cells were rare. However, cellular heterogeneity is also a histological feature of many melanomas, and studies of cell surface marker expression indicate that multiple, phenotypically distinct subpopulations of melanoma cells exist within tumors (Fang et al., 2005; Quintana et al., 2008; Schatton et al., 2008).

The basis of this heterogeneity has been the subject of intense debate among melanoma biologists - and rightfully so. If melanoma cell heterogeneity develops in the context of a CSC model, then separate identification, study and therapeutic targeting of the rare tumorigenic cell population should result in great clinical benefit to patients. Furthermore, studying melanoma tumors as a whole is likely to mask the critical drivers of melanoma progression if these drivers are only present in a rare minority of the cells. However, if a high proportion of melanoma cells has tumorigenic potential and is subject to ongoing and extensive genetic and/or epigenetic change, the implications for managing this disease would be profound. For example, targeting single oncogenic mechanisms to which tumors are supposedly 'addicted' (Weinstein and Joe, 2008) may be only fleetingly beneficial in genetically unstable melanomas in which resistance mechanisms rapidly emerge. Similarly, cancer cells that are able to avoid therapeutic intervention by transiently switching to epigenetically-determined states of resistance may require a multipronged treatment approach (Sharma et al., 2010).

\section{Melanoma and the cancer stem cell model}

Several studies have correlated the phenotypic heterogeneity of melanoma cells with differences in cell behaviour. Fang et al. (2005) evaluated in vitro clonogenicity in melanoma cells by utilizing their ability to form spherical aggregates of cells in non-adherent culture conditions. Spherogenicity was identified in only a proportion of cells isolated from melanoma tumors, and at least some cells derived from spheres could form tumors when transplanted into immunocompromised mice. Heterogeneity of CD20 expression was noted among cells derived from melanoma sphere cultures, and cells from the $\mathrm{CD} 2 \mathrm{O}^{+}$subpopulation showed a greater capacity to form secondary spheres than $\mathrm{CD} 2 \mathrm{O}^{-}$cells, suggesting an association between marker expression and clonogenicity in cultured melanoma cells. In support of this concept, Gedye et al. (2009) identified subpopulations of $\mathrm{CD}_{133^{+}}$cells in early passage melanoma cell lines that displayed increased clonogenicity in soft agar culture compared with CD133- cells. Interestingly, in this study no differences in two-dimensional adherent growth were seen between cells according to expression of CD133, indicating that culture conditions can affect the evaluation of clonogenicity in melanoma cells.

An important question arising from these studies is whether the cells that were not clonogenic in vitro were tumorigenic in vivo. Tumorigenicity, a key component of malignant behaviour, is a property of cancer cells that by definition can only be demonstrated in vivo. Although clonogenic potential must exist in a cell for tumor formation to occur, it is not known how well the normal in vivo environment that supports clonogenic tumor growth in patients is recapitulated in vitro. In fact, melanoma cells isolated from patients are often difficult to grow in culture, despite displaying overt tumorigenicity. We have tested melanoma cells purified from six tumors obtained from patients with metastatic disease for their ability to form colonies in culture conditions that we have found to be supportive of melanoma cell growth (Fig. 1a). Each melanoma contained a high proportion $(13 \%-70 \%)$ of cells with tumorigenic potential when evaluated in immunocompromised NOD/SCID IL2R $\gamma^{-/-}$(NSG) mice, a highly permissive model for this purpose (Quintana et al., 2008). However, only four of these melanomas contained cells that proliferated and formed colonies in non-adherent culture. In three experiments, we also cultured cells adherently after plating on tissue culturetreated plastic (adherent culture on Matrigel did not increase the detectable frequency of clonogenic cells compared to culture on plastic; data not shown). Although the frequency of detectable clonogenic cells was generally higher in adherent culture than in non-adherent culture (Fig. 1a), in most cases the proportion of colony-forming cells identified in any culture condition was several-fold lower than the proportion of tumor-forming cells identified in NSG mice (Fig. 1a). Notably, 
a

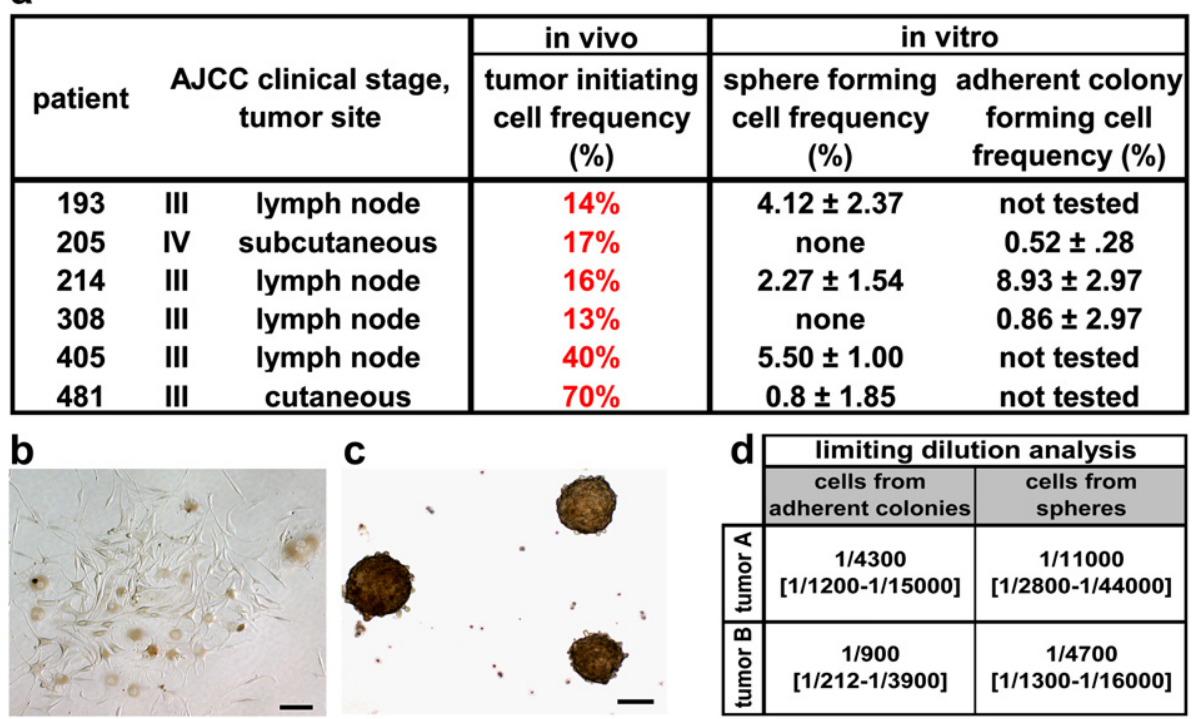

Figure 1 - In vitro culture of human melanoma cells. (A) Comparison of the in vivo tumorigenicity and the in vitro clonogenicity of melanoma cells. The frequency of tumorigenic cells was evaluated in melanomas obtained from six patients by limiting dilution or single cell transplantation assays into NSG mice (Quintana et al., 2008). Cells from the same tumors were also grown in vitro non-adherently (using ultra-low binding 6-well plates (Corning)) and in some cases adherently (using tissue culture-treated 6-well plates (Corning)) at clonal density using otherwise identical culture conditions (6.5\% CO2) and media (50\% DMEM-low, 30\% Neurobasal (Invitrogen), 15\% CEE (Stemple and Anderson, 1992), 1\% Pen/ Strep, 1\% non-essential amino acids (Gibco), $117 \mathrm{nM}$ retinoic acid, $50 \mu \mathrm{M}$ 2-mercaptoethanol, (Sigma), 1\% N2 supplement, 2\% B27 supplement (Gibco), $20 \mathrm{ng} / \mathrm{mL}$ recombinant human bFGF, $20 \mathrm{ng} / \mathrm{mL}$ IGF-1 (R\&D systems)). In vitro clonogenicity is shown as the mean ( \pm s.d.) percentage of plated cells that formed colonies in either culture condition (percentages derived from up to four independent experiments per melanoma, each one including cells plated into three separate wells). In some experiments, cells were cultured side-by-side either on tissue culture-treated plastic or after embedding cells in 25\% Matrigel. No significant differences were observed in the frequency of clonogenic cells identified in either of these adherent culture conditions (data not shown). The frequency of clonogenic cells identified in vitro was in every case lower than the empirically determined tumorigenic cell frequency in NSG mice. In two melanomas (205 and 308) that displayed robust tumorigenicity in NSG mice, melanomaspheres could not be generated at all and adherent colony formation was poor. Overall, in vitro clonogenicity was a poor surrogate for in vivo tumorigenicity in these experiments. $(B-C)$ Representative pictures of adherent $(B)$ and non-adherent spherogenic $(C)$ colony formation in primary human melanoma cell cultures (cells derived from patient 214, see A). (D) Cells obtained from two different patients and cultured either adherently or non-adherently (A) for 3 weeks were transplanted subcutaneously into NOD/SCID mice. Limiting dilution analysis (Hu and Smyth, 2009) was used to calculate the frequency of tumorigenic cells derived in each culture condition, based on the proportion of tumors that developed in mice per transplanted cell number. Tumorigenic cell frequencies were similar in human melanoma cells cultured adherently and non-adherently.

when we used limiting dilution analysis to calculate the frequency of cells in each culture condition that were tumorigenic in vivo, no significant differences were apparent between cells cultured adherently or non-adherently (Fig. 1b-d). Although these latter experiments were performed using suboptimal tumorigenesis assays (NOD/SCID mice without Matrigel) and the observations need to be confirmed in more permissive assays (NSG mice with Matrigel), the data suggest that in comparison with adherent culture, non-adherent culture does not enhance the maintenance of tumorigenic melanoma cells. We thus find that in vitro clonogenicity is an inadequate surrogate for melanoma cell tumorigenicity, at least in commonly used culture conditions. The development of in vitro assays that reliably predict in vivo malignant potential of melanoma cells is a high priority in melanoma research.

Other studies have tested directly the tumorigenicity of phenotypically distinct human melanoma cells using in vivo tumorigenesis assays. The approach in these studies is appealing because cells were isolated and transplanted directly from tumors, without an intervening in vitro culture step.
Because of this, artificial changes in malignant potential that may be induced in cancer cells through extended ex vivo manipulation are minimized. Indeed, the tremendous progress and enthusiasm in the CSC field over the last 10-15 years can be largely attributed to the development of immunocompromised mouse models that permit the growth of human cancer cells obtained directly from patient tumors. Monzani et al. (2007) found that CD133 expression was associated with increased tumorigenicity in cells isolated directly from seven metastatic patient tumors and evaluated by transplantation into immunocompromised NOD/SCID mice. In this study, injection of $\mathrm{CD}_{133^{+}}$cells produced tumors in the mice after only 40-50 days, whereas no tumors arose from CD133- cells after 4 months. Similarly, Schatton et al. (2008) identified a subpopulation of human melanoma cells that was characterized by expression of the multidrug transporter molecule ABCB5 and by enriched tumorigenicity in NOD/SCID mice. In this study, the empirically determined overall frequency of tumorigenic cells in the melanomas studied was approximately 1 in a million, and the tumorigenic cell frequency 
in the $\mathrm{ABCB}^{+}$subpopulation was nearly 10 -fold higher. Importantly, targeting of $\mathrm{ABCB5}^{+}$cells with monoclonal antibodies inhibited tumor growth in xenograft melanoma models, highlighting the potential of identifying and targeting rare tumorigenic cells in cancer therapy. Collectively, these studies suggested that melanoma could propagate according to a CSC model in which tumorigenic cells were rare and gave rise to phenotypically distinct non-tumorigenic cells in a stable and hierarchical manner.

\section{Evidence that melanoma does not follow a cancer stem cell model}

However, other studies of melanoma cell tumorigenicity suggest that this may not be the case. In light of reports that raised questions about the effects of xenotransplantation on the detection of human cell tumorigenicity by showing that tumorigenic cells were not rare in syngeneic transplantation studies of mouse cancers (Kelly et al., 2007; Williams et al., 2007), we decided to re-evaluate the human melanoma tumorigenesis assay. These experiments revealed three parameters that affected the ability of human melanoma cells to form tumors in immunodeficient mice: 1) assay duration, 2) the degree of immunodeficiency in recipient mice, and 3) the immediate extracellular environment into which melanoma cells are transplanted. When we altered the tumorigenesis assay to include a longer post-transplant monitoring time, the use of NSG mice as recipients, and pre-embedding cells in Matrigel prior to transplantation, we observed a roughly 5000 -fold increase in the ability to detect tumorigenic melanoma cells compared with published assay conditions (Quintana et al., 2008). In a series of extended experiments evaluating in these modified assay conditions cells obtained directly from six patients with metastatic melanoma, the average frequency of tumorigenic cells was 25\% (Quintana et al., 2008). The simplest interpretation of these experiments is that metastatic melanoma contains a high proportion of cells with intrinsic tumorigenic potential that are not apparent when tumorigenicity is evaluated in assays less permissive for allowing tumor formation.

Since then, others have also found clonogenicity and/or tumorigenicity to be present in a high proportion of melanoma cells. Prasmickaite et al. (2010) demonstrated that a high proportion of melanoma cells in established cultures could be clonogenic. Zhong et al. (2010) found that $>10 \%$ of cells in the B16F10 mouse melanoma cell line were tumorigenic in the context of syngeneic transplantation. Held et al. (2010) found tumorigenicity to be a common property of melanoma cells in different mouse models. Notably in this study, single cells isolated from the large $\mathrm{CD} 34^{+}$fraction of tumors carrying an activated BRAF mutation and lacking the tumor suppressor PTEN formed a tumor in every case (six secondary tumors arose from six CD34 $4^{+}$ single cell injections in two independent experiments). This indicates that a large proportion of melanoma cells in this model have tumorigenic potential. Interestingly, evidence of hierarchical organization was not present in the highly tumorigenic $\mathrm{CD} 4^{+}$fraction, but was observed in less-tumorigenic CD34 cells, which were distinguished by $\mathrm{p} 75$ expression; CD34 ${ }^{-} \mathrm{p} 75^{-}$ cells produced tumors containing both $\mathrm{p} 75^{-}$and $\mathrm{p} 75^{+}$fractions, whereas $\mathrm{CD} 34^{-} \mathrm{p} 75^{+}$cells were not tumorigenic in single cell tumorigenesis assays. This raises the possibility that ongoing mutations in transformed cells may produce biologically distinct tumorigenic clones within the same tumor: those that produce non-tumorigenic cells and those that do not. Overall, these studies and our own results support the conclusion that tumorigenic potential is frequently present in melanoma cells and indicate that this disease does not progress according to a CSC model characterized by rare tumorigenic cells.

\section{The NSG tumorigenesis assay}

Could the NSG tumorigenesis assay overestimate tumorigenic potential in melanoma cells? We believe not, as by definition potential can never be overestimated, only concealed. It is highly unlikely that non-tumorigenic melanoma cells were rendered tumorigenic by exposure to Matrigel or the subcutaneous tissues of NSG mice, as the same assay conditions did not transform normal human melanocytes (Quintana et al., 2008). Therefore, the transplanted cells that formed tumors must have harbored an intrinsic potential to do so. During neoplastic transformation a cell acquires malignant potential, including the capacity for tumor formation. In a patient, this potential may not be apparent in every cell at every moment. For example, some cells may be actively proliferating and others dormant, in part regulated by environmental influences. However, the non-proliferating cells can be said to harbor tumorigenic potential if in a different circumstance they proliferate actively and contribute to tumor formation. In a conceptually similar way, a cancer cell may still have tumorigenic potential, even if a particular assay does not reveal it. This can be shown if other assay conditions allow that same cell to form tumors. We contend that the NSG tumorigenesis assay does not make melanoma cells tumorigenic. Rather, it reveals tumorigenic potential that is already present in cells but can be hidden in other assays.

Of course, not every cell with tumorigenic potential will contribute to melanoma progression in a patient. Tumorigenic potential in some melanoma cells may be transiently or permanently suppressed in patients by cell-extrinsic mechanisms, such as anti-tumor immune effects or metabolic insufficiency. Some cells may even be killed by these mechanisms. Additionally, tumorigenic potential could be irreversibly lost in some cells through cell-intrinsic mechanisms, such as stable epigenetic changes (as proposed in the CSC model) or the acquisition of deleterious genetic changes (that could occur in the context of clonal evolution). In a patient, it is not possible to test which cells with tumorigenic potential will and will not propagate disease, as in vivo studies of syngeneic human melanoma cell transplantation are not ethical. Therefore, a cell that is demonstrated to be intrinsically tumorigenic in any assay system should be considered to be potentially tumorigenic in a patient. It is not safe to ignore in therapy cancer cells that are non-tumorigenic only under certain assay conditions.

A further question arising from our studies of melanoma cell tumorigenicity in NOD/SCID and NSG mice regards the potential role of natural killer (NK) cell function in modifying the course of melanoma progression in patients. NSG mice differ 
from NOD/SCID mice in being depleted of NK cell function (Shultz et al., 2005). In side-by-side assays comparing directly melanoma cell tumorigenicity in NOD/SCID vs NSG mice, we found up to over 100-fold increase in the frequency of tumorigenic cells in the NSG model (Quintana et al., 2008). This suggests a critical role for NK cells in inhibiting the tumorigenicity of human melanoma cells in NOD/SCID mice. However, care must be taken in extrapolating these results to the ways in which NK cells in patients may limit human melanoma progression. The xenogeneic immune response in NOD/SCID mice against human melanoma cells is likely to be fundamentally different to the immune response mounted by patients against their own melanoma. NK cells may be important in the xenogeneic rejection of transplanted cells (Yang and Sykes, 2007), but strong evidence of dominant NK cell-mediated anti-tumor effects in patients, equivalent to the elimination of the vast majority of transplanted human melanoma cells we observed in NOD/SCID mice, is lacking (Wallace and Smyth, 2005). Efforts to understand and enhance NK cell killing of cancer cells in patients are clearly worthwhile, but our experience comparing human melanoma cell tumorigenesis in NSG and NOD/SCID mice does not necessarily justify them.

\section{The nature of tumorigenic melanoma cells}

If melanoma does not follow a cancer stem cell model characterized by rare tumorigenic cells, a fundamental question then arises as to how the disease grows and spreads with such frequently lethal rapidity in patients. Specifically, to what degree do interconversion and clonal evolution play a role in determining the nature of the large and highly malignant tumorigenic cell component of these cancers? Currently, the answers to these questions are unknown. However, evidence exists that both models of cancer progression may be relevant to understanding the mechanisms that drive melanoma propagation.

For interconversion, there is evidence that melanoma cells can display plasticity. For example, phenotypic (Bennett, 1983) and functional (Hoek et al., 2008) switching of melanoma cells between different states of cell pigmentation and proliferation, respectively, has been described. Expression of Brn-2, a mediator of melanocyte differentiation through its repressive effects on MITF, was observed by intra-vital imaging to be heterogeneously and transiently present in transplanted tumors derived from the B16 mouse melanoma cell line, and associated with reduced pigmentation and increased cell invasiveness (Pinner et al., 2009). JARID1B, which modulates chromatin structure via demethylase activity at histone $3 \mathrm{~K} 4$, was found to be heterogeneously and reversibly expressed in melanoma cell lines in a way that correlated with an enhanced ability to support long-term tumorigenesis (Roesch et al., 2010). Our own studies of expression of the cell surface marker CD133 have identified heterogeneous expression in some melanomas. In contrast to other cancers (O'Brien et al., 2007; Ricci-Vitiani et al., 2007; Singh et al., 2004), we have found no evidence that this marker is enriched in tumorigenic melanoma cells (Quintana et al., 2008). Additionally, when we evaluated CD133 expression in secondary tumors derived from purified $\mathrm{CD} 133^{-}$or $\mathrm{CD} 133^{+}$ cells, similarly heterogeneous expression was seen in all tumors irrespective of their cellular origin (Shackleton et al.,
2009). This indicates that expression of CD133 is not a heritable trait of melanoma cells in tumors, but rather determined as a result of reversible factors. A high priority in melanoma research is to understand the functional significance of melanoma cell interconversion and its relationship to transitory changes in the malignant behaviour of cells.

For clonal evolution, there is evidence that heterogeneous genetic changes can evolve within a melanoma tumor. For example, sampling of multiple and separate intratumoral regions identified frequent differences in the genomic regions evaluated (Takata et al., 2000). A critical question that arises from this observation regards the functional significance of the development of such genetic heterogeneity; which genetic changes in cells cause changes in malignant potential? One example is the amplification in chromosome 13 identified as a driver of the spontaneous development of metastatic capability in some melanoma cells through resultant overexpression of NEDD9 (Kim et al., 2006). Another implication of the effects of genetic instability in melanoma cells is the possibility that additional genetic mutations may confer resistance to therapy, a phenomenon described in other cancers (Edwards et al., 2008; Sakai et al., 2008; Shah et al., 2007). The clinical importance of this was further highlighted by the identification of concurrent oncogenic mechanisms that could switch mutant BRAF-driven cells from a state of sensitivity to BRAF-inhibition to a state whose malignant behaviour is enhanced by BRAF-inhibition (Heidorn et al., 2010). Clonal evolution likely plays an important role in determining the outcome of melanoma in patients. For this reason, determining the degree and rate of genetic change among melanoma cells is also a high priority in melanoma research, particularly efforts to identify those genetic changes that drive the acquisition of enhanced malignant potential or therapy resistance.

\section{Conclusion}

Significant progress has been made in understanding the mechanisms through which established melanomas progress. This has led to the recent development of arguably the most exciting potential advance in therapy yet seen in this disease, BRAF-inhibition (Flaherty et al., 2009), for which definitive clinical trials are currently underway. However the identification of resistance mechanisms to BRAF inhibitors (Emery et al., 2009) and the fact that many melanomas do not carry suitable mutations (Davies et al., 2002) indicate that much work remains to be done in understanding the nature of melanoma propagation.

While the CSC model offers hope for improved treatment of some cancers by focusing research and therapies at rare populations of tumorigenic cells, it is apparent that not all cancers follow a CSC model. Although evidence from earlier studies suggested that melanoma might follow a CSC model, recent studies in more permissive tumorigenesis assays argue strongly against this possibility. Effective treatments for melanoma will thus have to account for the fact that a high proportion of cells must be eliminated. The focus of research efforts needs to be firmly on unraveling the mechanisms that promote growth, metastasis and therapy evasion in the cells with tumorigenic potential that are so abundant in this disease. 


\section{Acknowledgements}

Thanks to Sean Morrison and Mark Smyth for helpful comments. This work was supported by the Howard Hughes Medical Institute. M.S. was supported by the Peter MacCallum Cancer Centre, the Australian National Health and Medical Research Council, the Human Frontiers Science Program, and Australia Post. E.Q. was supported by the Spanish Ministry of Education and the Marie Curie Outgoing International Fellowship from the European Commission. Apologies to authors whose work was not cited due to space limitations.

\section{Note added in proof}

As this review was going to press, a publication from Weissman and colleagues appeared in Nature claiming to identify enriched tumorigenic capacity in the CD271/NGFR/p75 ${ }^{+}$subfraction of human melanoma cells (Boiko et al., 2010). In the central experiments of the paper, the authors purified melanoma cells from patient tumors (5/6 of the tumors studied were metastatic lesions - see Supp Tables 2 and 3) before performing intradermal transplants of cells into immunocompromised Rag2 ${ }^{-1-} \mathrm{\gamma C}^{-1-}$ mice. In transplants of unfractionated cells from three tumors, large numbers $(\geq 1000)$ of cells were generally required to generate tumors. Using limiting dilution analysis of the data (Hu and Smyth, 2009), the maximum frequency of tumorigenic cells in unfractionated populations in any tumor was $1 / 2270$ (95\% confidence interval 1/550 - 1/9,400, Supp Table 3, tumor 213). This contrasts starkly with our studies of six melanomas obtained directly from patients in which the minimum frequency of tumorigenic cells in unfractionated populations was $1 / 6$ (95\% confidence interval 1/2 - 1/15) (Quintana et al., 2008, Fig 3c, tumors 487, 491 and 498). Furthermore, although Boiko et al. found that in 5/6 melanomas studied there was statistically significant $(p<0.05)$ enrichment of tumorigenic potential in the CD271/NGFR/p75 $5^{+}$fraction, our own studies of melanoma cells separated according to CD271/NGFR/p75 $5^{+}$ expression and transplanted in more permissive tumorigenesis assay conditions have not revealed a similar effect (unpublished). The reasons for these differences are not clear, but are likely related to differences in the tumorigenesis assays used (different tumor digestion protocols, different recipient mice, different injection sites). It will be important for melanoma biologists to evaluate independently these results by carefully reproducing the experimental conditions used in each study. Regardless, studies of the nature and regulation of tumorigenic melanoma cells hold the best hope of revealing new therapeutic strategies to combat this disease.

R E F E R E N C E S

Bennett, D.C., 1983. Differentiation in mouse melanoma cells: initial reversibility and an on-off stochastic model. Cell 34, 445-453.

Boiko, A.D., Razorenova, O.V., van de Rijn, M., Swetter, S.M., Johnson, D.L., Ly, D.P., Butler, P.D., Yang, G.P., Joshua, B., Kaplan, M.J., Longaker, M.T., Weissman, I.L., 2010. Human melanoma-initiating cells express neural crest nerve growth factor receptor CD271. Nature 466, 133-137.

Davies, H., Bignell, G.R., Cox, C., Stephens, P., Edkins, S., Clegg, S., Teague, J., Woffendin, H., Garnett, M.J., Bottomley, W., Davis, N., Dicks, E., Ewing, R., Floyd, Y., Gray, K., Hall, S., Hawes, R., Hughes, J., Kosmidou, V., Menzies, A., Mould, C., Parker, A., Stevens, C., Watt, S., Hooper, S., Wilson, R., Jayatilake, H., Gusterson, B.A., Cooper, C., Shipley, J., Hargrave, D., PritchardJones, K., Maitland, N., Chenevix-Trench, G., Riggins, G.J., Bigner, D.D., Palmieri, G., Cossu, A., Flanagan, A., Nicholson, A., Ho, J.W., Leung, S.Y., Yuen, S.T., Weber, B.L., Seigler, H.F., Darrow, T.L., Paterson, H., Marais, R., Marshall, C.J., Wooster, R., Stratton, M.R., Futreal, P.A., 2002. Mutations of the BRAF gene in human cancer. Nature 417, 949-954.

Dick, J.E., 2008. Stem cell concepts renew cancer research. Blood 112, 4793-4807.

Edwards, S.L., Brough, R., Lord, C.J., Natrajan, R., Vatcheva, R., Levine, D.A., Boyd, J., Reis-Filho, J.S., Ashworth, A., 2008. Resistance to therapy caused by intragenic deletion in BRCA2. Nature 451, 1111-1115.

Emery, C.M., Vijayendran, K.G., Zipser, M.C., Sawyer, A.M., Niu, L., Kim, J.J., Hatton, C., Chopra, R., Oberholzer, P.A., Karpova, M.B., MacConaill, L.E., Zhang, J., Gray, N.S., Sellers, W.R., Dummer, R., Garraway, L.A., 2009. MEK1 mutations confer resistance to MEK and B-RAF inhibition. Proc. Natl. Acad. Sci. U S A 106, 20411-20416.

Fang, D., Nguyen, T.K., Leishear, K., Finko, R., Kulp, A.N., Hotz, S., Van Belle, P.A., Xu, X., Elder, D.E., Herlyn, M., 2005. A tumorigenic subpopulation with stem cell properties in melanomas. Cancer Res. 65, 9328-9337.

Fearon, E.R., Vogelstein, B., 1990. A genetic model for colorectal tumorigenesis. Cell 61, 759-767.

Flaherty, K., Puzanov, I., Sosman, J., Kim, K., Ribas, A., McArthur, G., Lee, R.J., Grippo, J.F., Nolop, P., Chapman, P., 2009. Phase 1 study of PLX4032: Proof of concept for V600E BRAF mutationas a therapeutic target in human cancer. J. Clin. Oncol. 27 suppl; abstr 9000.

Foulds, L., 1958. The natural history of cancer. J. Chronic Dis. 8, 2-37.

Gedye, C., Quirk, J., Browning, J., Svobodova, S., John, T., Sluka, P., Dunbar, P.R., Corbeil, D., Cebon, J., Davis, I.D., 2009. Cancer/ testis antigens can be immunological targets in clonogenic $\mathrm{CD}_{133^{+}}$melanoma cells. Cancer Immunol. Immunother. 58, 1635-1646.

Gupta, P.B., Chaffer, C.L., Weinberg, R.A., 2009. Cancer stem cells: mirage or reality? Nat. Med. 15, 1010-1012.

Heidorn, S.J., Milagre, C., Whittaker, S., Nourry, A., NiculescuDuvas, I., Dhomen, N., Hussain, J., Reis-Filho, J.S., Springer, C.J., Pritchard, C., Marais, R., 2010. Kinase-dead BRAF and oncogenic RAS cooperate to drive tumor progression through CRAF. Cell 140, 209-221.

Held, M.A., Curley, D.P., Dankort, D., McMahon, M., Muthusamy, V., Bosenberg, M.W., 2010. Characterization of melanoma cells capable of propagating tumors from a single cell. Cancer Res. 70, 388-397.

Hoek, K.S., Eichhoff, O.M., Schlegel, N.C., Dobbeling, U., Kobert, N., Schaerer, L., Hemmi, S., Dummer, R., 2008. In vivo switching of human melanoma cells between proliferative and invasive states. Cancer Res. 68, 650-656.

Hu, S., Parmet, Y., Allen, G., Parker, D.F., Ma, F., Rouhani, P., Kirsner, R.S., 2009. Disparity in melanoma: a trend analysis of melanoma incidence and stage at diagnosis among whites, Hispanics, and blacks in Florida. Arch. Dermatol. 145, 1369-1374.

Hu, Y., Smyth, G.K., 2009. ELDA: extreme limiting dilution analysis for comparing depleted and enriched populations in stem cell and other assays. J. Immunol. Methods 347, 70-78.

Kelly, P.N., Dakic, A., Adams, J.M., Nutt, S.L., Strasser, A., 2007. Tumor growth need not be driven by rare cancer stem cells. Science 317, 337. 
Kim, M., Gans, J.D., Nogueira, C., Wang, A., Paik, J.H., Feng, B., Brennan, C., Hahn, W.C., Cordon-Cardo, C., Wagner, S.N., Flotte, T.J., Duncan, L.M., Granter, S.R., Chin, L., 2006. Comparative oncogenomics identifies NEDD9 as a melanoma metastasis gene. Cell 125, 1269-1281.

Lengauer, C., Kinzler, K.W., Vogelstein, B., 1998. Genetic instabilities in human cancers. Nature 396, 643-649.

Lobo, N.A., Shimono, Y., Qian, D., Clarke, M.F., 2007. The biology of cancer stem cells. Annu. Rev. Cell Dev. Biol. 23, 675-699.

Mani, S.A., Guo, W., Liao, M.J., Eaton, E.N., Ayyanan, A., Zhou, A.Y., Brooks, M., Reinhard, F., Zhang, C.C., Shipitsin, M., Campbell, L.L., Polyak, K., Brisken, C., Yang, J., Weinberg, R.A., 2008. The epithelial-mesenchymal transition generates cells with properties of stem cells. Cell 133, 704-715.

Marusyk, A., Polyak, K., 2010. Tumor heterogeneity: causes and consequences. Biochim. Biophys. Acta 1805, 105-117.

Monzani, E., Facchetti, F., Galmozzi, E., Corsini, E., Benetti, A. Cavazzin, C., Gritti, A., Piccinini, A., Porro, D., Santinami, M., Invernici, G., Parati, E., Alessandri, G., La Porta, C.A., 2007. Melanoma contains CD133 and ABCG2 positive cells with enhanced tumourigenic potential. Eur. J. Cancer 43, 935-946.

Nowell, P.C., 1976. The clonal evolution of tumor cell populations. Science 194, 23-28.

O'Brien, C.A., Pollett, A., Gallinger, S., Dick, J.E., 2007. A human colon cancer cell capable of initiating tumour growth in immunodeficient mice. Nature 445, 106-110.

Ohsie, S.J., Sarantopoulos, G.P., Cochran, A.J., Binder, S.W., 2008. Immunohistochemical characteristics of melanoma. J. Cutan. Pathol. 35, 433-444.

Pinner, S., Jordan, P., Sharrock, K., Bazley, L., Collinson, L., Marais, R., Bonvin, E., Goding, C., Sahai, E., 2009. Intravital imaging reveals transient changes in pigment production and Brn2 expression during metastatic melanoma dissemination. Cancer Res. 69, 7969-7977.

Prasmickaite, L., Skrbo, N., Hoifodt, H.K., Suo, Z., Engebraten, O., Gullestad, H.P., Aamdal, S., Fodstad, O., Maelandsmo, G.M., 2010. Human malignant melanoma harbours a large fraction of highly clonogenic cells that do not express markers associated with cancer stem cells. Pigment Cell Melanoma Res..

Quintana, E., Shackleton, M., Sabel, M.S., Fullen, D.R., Johnson, T.M., Morrison, S.J., 2008. Efficient tumour formation by single human melanoma cells. Nature 456, 593-598.

Reya, T., Morrison, S.J., Clarke, M.F., Weissman, I.L., 2001. Stem cells, cancer, and cancer stem cells. Nature 414, 105-111.

Ricci-Vitiani, L., Lombardi, D.G., Pilozzi, E., Biffoni, M., Todaro, M., Peschle, C., De Maria, R., 2007. Identification and expansion of human colon-cancer-initiating cells. Nature 445, 111-115.

Roesch, A., Fukunaga-Kalabis, M., Schmidt, E.C., Zabierowski, S.E., Brafford, P.A., Vultur, A., Basu, D., Gimotty, P., Vogt, T., Herlyn, M., 2010. A temporarily distinct subpopulation of slowcycling melanoma cells is required for continuous tumor growth. Cell 141, 583-594.

Sakai, W., Swisher, E.M., Karlan, B.Y., Agarwal, M.K., Higgins, J., Friedman, C., Villegas, E., Jacquemont, C., Farrugia, D.J., Couch, F.J., Urban, N., Taniguchi, T., 2008. Secondary mutations as a mechanism of cisplatin resistance in BRCA2mutated cancers. Nature 451, 1116-1120.

Schatton, T., Murphy, G.F., Frank, N.Y., Yamaura, K., WaagaGasser, A.M., Gasser, M., Zhan, Q., Jordan, S., Duncan, L.M., Weishaupt, C., Fuhlbrigge, R.C., Kupper, T.S., Sayegh, M.H., Frank, M.H., 2008. Identification of cells initiating human melanomas. Nature 451, 345-349.

Shackleton, M., 2010. Normal stem cells and cancer stem cells: similar and different. Semin Cancer Biol. 20, 85-92.

Shackleton, M., Quintana, E., Fearon, E.R., Morrison, S.J., 2009. Heterogeneity in cancer: cancer stem cells versus clonal evolution. Cell 138, 822-829.

Shah, N.P., Skaggs, B.J., Branford, S., Hughes, T.P., Nicoll, J.M., Paquette, R.L., Sawyers, C.L., 2007. Sequential ABL kinase inhibitor therapy selects for compound drug-resistant BCRABL mutations with altered oncogenic potency. J. Clin. Invest. $117,2562-2569$.

Sharma, S.V., Lee, D.Y., Li, B., Quinlan, M.P., Takahashi, F., Maheswaran, S., McDermott, U., Azizian, N., Zou, L., Fischbach, M.A., Wong, K.K., Brandstetter, K., Wittner, B., Ramaswamy, S., Classon, M., Settleman, J., 2010. A chromatinmediated reversible drug-tolerant state in cancer cell subpopulations. Cell 141, 69-80.

Shultz, L.D., Lyons, B.L., Burzenski, L.M., Gott, B., Chen, X., Chaleff, S., Kotb, M., Gillies, S.D., King, M., Mangada, J., Greiner, D.L., Handgretinger, R., 2005. Human lymphoid and myeloid cell development in NOD/LtSz-scid IL2R gamma null mice engrafted with mobilized human hemopoietic stem cells. J. Immunol. 174, 6477-6489.

Singh, S.K., Hawkins, C., Clarke, I.D., Squire, J.A., Bayani, J., Hide, T., Henkelman, R.M., Cusimano, M.D., Dirks, P.B., 2004. Identification of human brain tumour initiating cells. Nature 432, 396-401.

Stemple, D.L., Anderson, D.J., 1992. Isolation of a stem cell for neurons and glia from the mammalian neural crest. Cell 71, 973-985.

Takata, M., Morita, R., Takehara, K., 2000. Clonal heterogeneity in sporadic melanomas as revealed by loss-of-heterozygosity analysis. Int. J. Cancer 85, 492-497.

Tsao, H., Atkins, M.B., Sober, A.J., 2004. Management of cutaneous melanoma. N. Engl. J. Med. 351, 998-1012.

Wallace, M.E., Smyth, M.J., 2005. The role of natural killer cells in tumor control-effectors and regulators of adaptive immunity. Springer Semin. Immunopathol 27, 49-64.

Weatherhead, S.C., Haniffa, M., Lawrence, C.M., 2007. Melanomas arising from naevi and de novo melanomas-does origin matter? Br. J. Dermatol. 156, 72-76.

Weinstein, I.B., Joe, A., 2008. Oncogene addiction. Cancer Res. 68, 3077-3080. discussion 3080.

Williams, R.T., den Besten, W., Sherr, C.J., 2007. Cytokinedependent imatinib resistance in mouse BCR-ABL+, Arf-null lymphoblastic leukemia. Genes Dev. 21, 2283-2287.

Yang, Y.G., Sykes, M., 2007. Xenotransplantation: current status and a perspective on the future. Nat. Rev. Immunol. 7, 519-531.

Zhong, Y., Guan, K., Zhou, C., Ma, W., Wang, D., Zhang, Y., Zhang, S., 2010. Cancer stem cells sustaining the growth of mouse melanoma are not rare. Cancer Lett. 292, 17-23. 